\title{
Concomitant Therapy
}

National Cancer Institute

\section{Source}

National Cancer Institute. Concomitant Therapy. NCI Thesaurus. Code C53630.

Any pharmaceutical agent, other than the primary therapy, that is administered to or used by the subject prior to or during a specified time period. 